\title{
Unrolling the text: Using scrolls to facilitate academic reading
}

\section{Sandra Abegglen}

Independent academic

\section{Tom Burns}

London Metropolitan University, United Kingdom

\section{David Middlebrook}

Independent academic

\section{Sandra Sinfield}

London Metropolitan University, United Kingdom

\section{Abstract}

This case study shows how we have used textscrolls to address academic reading in our Facilitating Student Learning postgraduate module. We outline how we explored with staff the potential of the textscroll to offer a more welcoming, accessible, collaborative and dialogic encounter with reading than the codex (bound book or article). Drawing briefly on a literature review commissioned when part of the LearnHigher Centre for Excellence in Teaching and Learning, we consider reading not just as a semantic or linguistic activity but as a socio-political one, especially for those, like our students, who are typically placed as educational outsiders. We harness the work of Dave Middlebrook (one of our co-authors) and his discussion of the power relations of the bound text and the liberatory potential of the unrolled textscroll. We conclude with an example of what happened when one of our staff participants took scrolls back to her third year Design students, and we argue that utilising emancipatory teaching practices can make higher education more inclusive.

Keywords: textscrolls; academic reading; higher education; staff development; emancipatory teaching; inclusion. 


\section{Introduction}

At London Metropolitan University we recruit culturally diverse mature students with care and work commitments, some of whom have diagnosed learning disabilities (London Metropolitan University, 2018). In the Centre for Professional and Educational Development (CPED) we are tasked with providing certificated and non-certificated staff development - with a focus on emancipatory practice and Association for Learning Development in Higher Education (ALDinHE) values (Association for Learning Development in Higher Education, 2018). The focus of this paper is how we work with discipline staff to enhance the way that they develop academic reading strategies with their undergraduate students. Specifically, we discuss how we have used unrolled textscrolls (Middlebrook, 2018) to address academic reading in our Facilitating Student Learning (FSL) module, which forms part of our PGCert (Postgraduate Certificate) in Learning and Teaching in Higher Education. We outline how we explored with our FSL participants the potential of the textscroll to offer a more welcoming, accessible, collaborative, and dialogic encounter with reading than the codex (bound book).

Drawing on a literature review commissioned when part of the LearnHigher CETL (Centre for Excellence in Teaching and Learning, 2005-2010), we consider reading not just as a semantic or linguistic activity but as a socio-political one (Freire, 1970) - one from which our non-traditional students typically feel excluded (Hoskins, 2008). Our argument is that using textscrolls with our students can empower especially those who are deemed to have little or no cultural or academic capital (Hoskins, 2008) and thus who are typically placed as education outsiders (Sinfield, Burns and Holley, 2004). Congruent with this approach we also draw on the work of Dave Middlebrook (one of our co-authors) and his discussion of the power relations of the bound book and the liberatory potential of the unrolled textscroll: the book unbound (Middlebrook, 2015; 1994a; 1994b; 1994c). We conclude with an example of what happened when one of our staff took the practice back to her third year Design students, and we argue, in line with ALDinHE, that utilising emancipatory teaching practices can make higher education (HE) more inclusive.

\section{Academic reading - an issue of social justice}


The LearnHigher CETL was funded for five years to produce resources and research to enable excellent HE practice (see: http://www.learnhigher.ac.uk/). One focus for us was the facilitation of successful academic reading practices. To initiate our project, we recruited a PhD student to undertake a literature review on the topic. Kate, a working-class graduate of a widening participation university, wrote the literature review online and in real time, whilst simultaneously blogging about her process of writing that literature review (see: http://litreview.pbworks.com/w/page/18059710/FrontPage and http://onlinelitreview.blogspot.com/2008/01/). In her exploration, she drew on her own experiences of exclusion, utilising Bourdieu's $(1977 ; 1984)$ concepts of cultural capital and institutional habitus, and Foucault's (Ball, 1990) concept of discourse, to make sense of the way that non-traditional students in particular experience the power imbalance of HE and especially of the power imbalance surrounding academic reading (see: http://litreview.pbworks.com/w/page/18059717/this\%20link). The literature review categorically placed reading at university as a socio-political activity, with widening participation students excluded by the middle-class habitus and discourse of HE. What was, and is, apparent is that those with greater social, cultural and academic capital tend to do better in HE than those without (Meuleman, Garrett, Wrench and King, 2015). Knowing this, the challenge for us was to enable academic staff to facilitate successful participation in university practices, especially reading, without creating or increasing negative experiences for our non-traditional students.

\section{Scrolls vs Conventional Academic Text Formats}

So, what might textscrolls have to do with academic reading as a socio-political activity?

We begin with the observation (Middlebrook, 1994a) that the printed journal or book's fundamental design - pages bound between covers - restricts and complicates how we approach a text and how we go about performing the various tasks that collectively comprise reading. When a student opens a book or prints off an article, they see a twopage display. That is the most that they can see at any one moment. They can fan the pages back and forth in order to gain some sense of the larger context but, in the end, they are left to discover and make sense of content that is fragmented and scattered across many pages. The unrolled scroll, in contrast, is wide-open to the reader. It offers an 
expansive, panoramic display of the content. In doing so, it reveals the structure and flow of ideas across the entire text.

Scrolls can be produced from articles or chapters, or other large chunks of texts (scrolling a whole book would be unwieldy). They can be displayed by unrolling them across walls, desktops or floor areas. A text displayed in this manner invites readers to get out of their chairs - to stand up and move about, to walk back and forth across the scroll's unrolled expanse, to engage with the text through movement and touch, to feel how their bodies scale to the 'bookspace', and to see and know, moment to moment, where they are in the text, where they have and have not been, and where they want to go next. Navigation across unrolled textscrolls is visual and physical and, perhaps for this reason, fast and intuitive. Readers can start anywhere and move to any part of the text. They can engage as they wish - in groups or individually. There is plenty of room to explore - to move in close so as to (in the ancient Germanic/Saxon sense of the words) physically nearstand and understand the details, and then step back to farstand the larger context (Onions, 1994).

We came to understand these observations after the fact - after seeing how much better our undergraduate students did with the textscroll's wide-open display. Scrolls allowed our students to explore and question the text in front of them; this positioned them powerfully in relation to the written word, and thus academic reading became something that helped them navigate academia and develop a sense of self-efficacy (Bandura, 1982) as they became academic on their own terms. We thus wanted to develop the practice in our PGCert classroom such that for staff as well, reading could unfold as a richly constructivist, socio-political process where our staff learners could see reading - and hopefully thus our students - differently.

\section{Our PGCert: How we unrolled the text}

As with our students, our academics also come from diverse cultures and backgrounds; from different HE systems across the globe and from different industries. When entering $\mathrm{HE}$ and teaching for the first time, they may feel just as disempowered as their students (Harrington, Sinfield and Burns, 2016). Moreover, because of their varied backgrounds they have philosophically multiple approaches to teaching and learning; this can make 
them also feel like outsiders pitched against traditional academics. The dilemma for our staff learners is how to ensure that their students can function critically and effectively and gain power and voice - in an environment that is familiar to neither of them. Our role in the PGCert is to help staff experience differing learning, teaching and assessment practices so that they feel enabled more confidently to empower their students to succeed. This involves sharing not only the creative and emancipatory practices that we have developed with our undergraduate students (Abegglen, Burns and Sinfield 2018; 2017; $2016 \mathrm{a} ; 2016 \mathrm{~b})$, but also the use of textscrolls to help staff see reading, and the teaching of reading, differently.

We create our textscrolls following the example of Middlebrook (1994d). We photocopy or print, on one side of the paper only, articles of sufficient relevance, interest and complexity to be of real use to our FSL students; typically enlarging them to $A 3$, for the enlarged text is more accessible. We tape the pages together side by side so that a scroll is produced often of some length. For our 2017/18 textscroll session we produced three such textscrolls - one per group - and gave our staff learners coloured felt tips and a set of questions and prompts to seed their active engagement with their text. The texts selected stemmed from the module reading list and would later be utilised for the module assessment, which made them meaningful for staff learners. We asked staff to notice what is going on in the text as a physical, constructed thing. We asked them to concentrate on structure, headings and paragraphs. This meant unrolling the text and moving about. Immediately choices had to be made as the staff decide whether to spread their scroll across the table, stick it on the wall or settle on the floor and cluster around. Propelled into this hands-on relationship with the text, participants were forced to interact peer-to-peer and self-to-scroll. There was instantly discussion and engagement, with each other and the text. Arguably, this engagement is understanding and farstanding (Onions, 1994; see above) enacted - the social and embodied engagement with the words presented on paper.

We deepen the staff-facing textscroll session by explaining how we undertake this activity with undergraduate students. Once undergraduate students have annotated a textscroll, we feed in a small assignment question to push the interaction further. Now students move from noticing the structures of a text, to seeking information in the text, and to answer a real assignment question. This gives engagement with the textscroll a different sense of 
urgency and purpose, yet in a collegiate and non-threatening mode. This is university praxis in meaningful action; as Angelo (1993, p.3) states: 'Students do learn more and better by becoming actively involved'. In addition, the use of textscrolls allows us to slow things down (Berg and Seeber, 2016), and through that to make room for exploring and thinking more deeply (Biggs and Tang (2007).

\section{What the lecturer did: The case study within}

There may be concern that this reading technique disadvantages those students who feel threatened by engaging with texts publicly and students with SpLD (Specific Learning Difficulty), especially those with dyslexia or dyspraxia, who need longer to comprehend texts; thus we share here, and with permission from the tutor concerned, an example of using textscrolls with Design students. This cohort typically has a larger proportion of students with dyslexia or dyspraxia than other courses (for reasons that need further research). The task this tutor has given her Design students was to illustrate texts produced by Literature students by capturing the meaning of those complex texts from an alien discipline. It appears that using textscrolls made this process more successful than in previous years:

In my last practical teaching session (Tuesday 23 Jan), I tried out the text-mapping exercise we were introduced to in Workshop 3. . . .

I made a scroll for each student of their assigned text. The students felt quite excited about receiving their texts in this unusual physical format. I asked them to fully unfurl their scrolls and find space to look at and interact with it, using highlighters and pens to mark out sections, highlight key words and phrases and activate some meaning from the text, treating it as a visual entity in a spatial dimension. ... .

I think it was useful for the students, there was a good energy in the room. The exercise was a fun and enjoyable way to break down a long-ish text and at least one student who started the session feeling very unsure and nervous about working with a text (on William Blake - an inspiring but potentially intimidating subject) went away more confident. I will certainly use the technique again. 
She related the success of this approach in particular to the dialogic (Bahktin, 1981) and social (Lave and Wenger, 1991) nature of textscrolls as well as the emancipatory approach to teaching and learning (Holt, 1970) they enable:

The exercise used a dialogic approach to classroom practice, helping to form a community of practice and bolster students' confidence in their ability to tackle the project in a way that would gain them a successful outcome (encouraging resilience and self-efficacy).

This taps into the Holtian idea that the learning process should not set students up for failure as in the traditional classroom. But rather, we can teach in ways that encourage students to question what they are looking at and being asked to do, rather than to answer the question (or respond to the brief) in a way that pleases the teacher (or the system).

This is something we have also experienced when using textscrolls with our staff learners. Textscrolls create powerful learning spaces that make content not only visible, but also accessible and explainable - powerful spaces in which to become, in the fullest sense, a reader, a thinker, an academic.

\section{In conclusion}

On our PGCert course, we wanted to harness the power of textscrolls to enable our staff participants to see both reading and their students through a different and more emancipatory lens. Typically our non-traditional undergraduate students feel excluded, and are positioned as excluded, by the university's habitus and particularly by the power and discourse of academic reading. We found that when using the bound text unbound, the scroll, our staff and their students experienced in an embodied way that academic reading could be dialogic, cooperative and discursive. Unrolled textscrolls offer a powerful learning experience de facto positioning readers differently towards a text. Rather than exclusion and alienation, dialogue and empathy (Rogers, 1959) are promoted as everybody engages with text, with meaning, and with each other. As expressed by a participant in one of Dave's workshops, this reading approach '... gave me the opportunity to walk in my 
students' shoes'. (Middlebrook, 1999). Hence, we encourage readers to unroll their conventional texts, and make scrolls part of their learning and teaching practice.

Coda: Dave Middlebrook, one of our co-authors, has experimented extensively with scrolls and he is interested in further projects with academic staff to explore the potential of scrolls in university learning and teaching. Please check his website for further details: http://www.textmapping.org/

\section{References}

Abegglen, S., Burns, T. and Sinfield, S. (2016a) 'Hacking assignment practice: Finding creativity and power in the fissures and cracks of learning and teaching', Journal of Learning Development in Higher Education, Issue 10.

Abegglen, S., Burns, T. and Sinfield, S. (2016b) 'The power of freedom: Setting up a multimodal exhibition with undergraduate students to foster their learning and help them to achieve', Journal of Peer Learning, 9, pp. 1-9.

Abegglen, S., Burns, T. and Sinfield, S. (2017) "'Really free!": Strategic interventions to foster students' academic writing skills', Journal of Educational Innovation, Partnership and Change, 3(1), pp. 251-255.

Abegglen, S., Burns, T. \& Sinfield, S. (2018) 'Drawing as a way of knowing: Visual practices as the route to becoming academic', Canadian Journal for Studies in Discourse and Writing/Rédactologie, 28, pp.173-185.

Angelo, T. A. (1993) 'A teacher's dozen: Fourteen general, research-based principles for improving higher learning in our classrooms', AAHE Bulletin, 45(8), pp. 3-7.

Association for Learning Development in Higher Education (2018) About: The Association for Learning Development in Higher Education [Online]. Available at: http://aldinhe.ac.uk/about/ (Accessed: 15 August 2018). 
Ball, S. J. (ed.) (1990) Foucault and education: Disciplines and knowledge. London: Routledge.

Bandura, A. (1982) 'Self-efficacy mechanism in human agency', American Psychologist, 37(2), pp.122-147.

Bakhtin, M. (1981) The dialogic imagination: Four essays, Austin: University of Texas Press.

Berg, M. and Seeber, B. (2016) The slow professor: Challenging the culture of speed in the academy, Toronto: University of Toronto Press.

Biggs, J. and Tang, C. (2007) Teaching for quality learning at university, Maidenhead: Open University Press.

Bourdieu, P. (1977) Outline of a theory of practice. New York: Cambridge University Press.

Bourdieu, P. (1984) Distinction: A social critique of the judgement of taste, Cambridge: Harvard University Press.

Freire, P. (1970) Pedagogy of the oppressed, New York: Continuum.

Harrington, K., Sinfield, S. and Burns, T. (2016) 'Student engagement', pp.106-124, in Pokorny, $\mathrm{H}$. and Warren, D. (ed.) Enhancing teaching practice in higher education, London: Sage.

Holt, J. (1970) What do I do Monday?, New York: Dutton.

Hoskins, K. (2008a) Literature review [Online]. Available at: http://onlinelitreview.blogspot.com (Accessed: 15 August 2018).

Hoskins, K. (2008b) Online literature review: Critical reading skills for students; an evolving literature review [Online]. Available at: 
http://litreview.pbworks.com/w/page/18059710/FrontPage (Accessed: 15 August 2018).

Hoskins, K. (2008c) Evolving literature review [Online]. Available at: http://litreview.pbworks.com/w/page/18059717/this\%20link (Accessed: 15 August 2018).

Lave, J. and Wenger, E. (1991) Situated learning: Legitimate peripheral participation. Cambridge: Cambridge University Press.

LearnHigher (2018) Teaching and learning resources [Online]. Available at: http://www.learnhigher.ac.uk/ (Accessed: 15 August 2018).

London Metropolitan University (2018) Our key statistics [Online]. Available at: https://www.londonmet.ac.uk/about/our-university/university-publications/keystatistics/ (Accessed 15 August 2018).

Meuleman A., Garrett, R., Wrench, A. and King, S. (2015) "Some people might say I'm thriving but...": Non-traditional students' experiences of university', International Journal of Inclusive Education, 19(5), pp.503-517.

Middlebrook, R. D. (1994a) Scrolls are the foundation [Online]. Available at: http://www.textmapping.org/scrolls.html (Accessed: 22 August 2018).

Middlebrook, R. D. (1994b) Using scrolls [Online]. Available at: http://www.textmapping.org/using.html (Accessed: 18 August 2018).

Middlebrook, R. D. (1994c) The benefits of scrolls and textmapping [Online]. Available at: http://www.textmapping.org/benefits.html (Accessed: 17 August 2018).

Middlebrook, R.D. (1994d) Making a scroll [Online]. Available at: http://www.textmapping.org/making.html (Accessed: 22 August 2018). 
Middlebrook, R. D. (1999) Comments from educators and students [Online]. Available at: http://www.textmapping.org/comments.html (Accessed: 17 August 2018).

Middlebrook, R. D. (2015) Why use scrolls? [Online]. Available at http://www.textmapping.org/whyUseScrolls.pdf (Accessed 17 August 2018).

Middlebrook, R.D. (2018) Overview of textmapping [Online]. Available at: http://www.textmapping.org/overview.html (Accessed: 04 December 2018).

Onions, C. T. (ed.) (1994) The Oxford dictionary of English etymology, Oxford: Clarendon Press.

Rogers, C. R. (1959) 'A theory of therapy, personality, and interpersonal relationships as developed in the client-centered framework', pp.184-256, in Koch, S. (ed.) Psychology: A study of a science, (Vol. 3, Formulations of the person and the social context), New York: McGraw Hill.

Sinfield, S., Burns, T. and Holley, D. (2004) 'Outsiders looking in or insiders looking out? Widening Participation in a post-1992 University Chapter', pp.137-152, in Satterthwaite, J., Atkinson, E. and Martin, W. (ed.) The disciplining of education: New languages of power and resistance, Stoke on Trent: Trentham Books.

\section{Author details}

Sandra Abegglen was formerly Senior Lecturer and Course Leader BA Hons Education Studies at London Metropolitan University, United Kingdom and is currently an independent academic based in Calgary, Canada.

Tom Burns is Senior Lecturer in Education and Learning Development in the Centre for Professional and Educational Development (CPED) at London Metropolitan University, United Kingdom. 
David Middlebrook invented the textmapping method and pioneered the use of scrolls and textmapping for classroom instruction. He has been collaborating in classrooms and conducting workshops for teachers since 1994.

Sandra Sinfield is Senior Lecturer in the Centre for Professional and Educational Development (CPED) at London Metropolitan University, United Kingdom. 